\title{
Group Diversification
}

\author{
Philipp Keller \\ Federal Office of Private Insurance, Schwanengasse 2, Bern CH-3003, Switzerland. \\ E-mail: Philipp.Keller@bpv.admin.ch
}

We present an approach to capture group-level diversification using legally binding capital and risk transfer instruments. The approach is used by the Swiss Solvency Test to quantify both group-level capital requirements and capital requirements for subsidiaries of insurance groups.

The Geneva Papers (2007) 32, 382-392. doi:10.1057/palgrave.gpp.2510131

Keywords: diversification; insurance groups; economic capital requirements

\section{Introduction}

We present the Swiss approach for setting capital requirement for insurance groups. The approach is consistent with the requirements for legal entities, but complements the legal entity regulation. It is a regulatory framework that allows for a consistent allocation of group-level diversification to different legal entities, thereby encouraging risk and capital management. The approach is part of a wider set of requirements on groups' risk and capital management. ${ }^{1}$ The Swiss approach is quite similar to and consistent with both the proposals by the Chief Risk Officer Forum ${ }^{2}$ and the joint proposal by the U.K. Treasury and FSA. ${ }^{3}$

\section{Diversification}

Diversification is an essential part of insurance. Without it, the spreading of risk of different exposures would not be possible. Diversification is a mathematical concept that can be proven to exist and the only question is how large the effect of diversification is.

Diversification relates to the fact that the capital requirement of the aggregate of two portfolios is smaller than or equal to the sum of the capital requirements of the separate portfolios, if the capital requirement is determined with a coherent, that is, sub-additive, risk measure. Diversification in the context of groups is concerned with the reduction of the capital requirements of the local subsidiaries since risks are situated in the different legal entities of the group.

The existence of diversification within a portfolio of insurance policies or between lines of business within the same legal entity is an uncontroversial fact; the amount of

\footnotetext{
${ }^{1}$ See also BPV (2006) and Luder (2007).

${ }^{2}$ CRO Forum (2005).

${ }^{3}$ HM Treasury \& FSA (2006).
} 
diversification, however, can be difficult to quantify. It is a function of both the dependency between the different risks (e.g. policies or portfolio of policies) and of the risk measure. We make a simple example to show the effects of the risk measure.

Consider two portfolios with the following distribution of claims

$$
Y_{i}= \begin{cases}0, & P=0.9925 \\ X_{i}, & P=0.0075\end{cases}
$$

where $X_{i}$ is iid with $X_{i}=U(0,1)$ for $i=1,2$.

If the risk measure is the Value at Risk at the 99 per cent confidence level, then $\operatorname{VaR}\left(Y_{i}\right)=0, i=1,2$ and the Value at Risk of the aggregated portfolio $Y_{1}+Y_{2}$ is approximately 0.33 . There is negative diversification in the sense that the risk measure for the aggregated portfolio is higher than the sum of the risk measures of the separate portfolios $Y_{1}$ and $Y_{2}$.

If however the risk measure is Tail Value at Risk at the 99 per cent confidence level, then TailVaR $\left(Y_{i}\right)=0.37$ and TailVaR for $Y_{1}+Y_{2}$ is 0.67 . In this case there is positive diversification as TailVaR $\left(Y_{1}\right)+\operatorname{TailVaR}\left(Y_{2}\right)<\operatorname{TailVaR}\left(Y_{1}+Y_{2}\right)$.

Given a coherent risk measure as for instance Tail Value at Risk, there is always positive $(\geqslant 0)$ diversification. The exact amount of diversification is a function of the dependency between the risks. Often linear correlations or copulas are used to describe the dependency structure between risks. Since in many cases there is not sufficient historical data so that a specific dependency structure can be fitted, one has to rely on theoretical models. Copulas - in contrast to linear correlation - can allow for tail dependency. It can often be observed that in stressed situations, for example, when financial markets collapse, risk factors move together. The modelling of causal relationships between risks, for example via underlying risk factors, is another way of arriving at a dependency structure.

A discussion of diversification within a group context has to focus also on an implicit assumption, namely that different portfolios (or risks) of legal entities can be aggregated. Diversification then is not purely a mathematical question anymore, but also concerns legal and regulatory aspects. To aggregate two portfolios assumes implicitly that capital can flow freely between the two legal entities. How far this is the case is treated within FOPI's (Federal Office for Private Insurance) approach by linking diversification to existing capital and risk transfer instruments (CRTIs).

When speaking of diversification in the context of groups, there are two distinct but interrelated concepts that have to be separated:

Group-level diversification: A parent company benefits endogenously from grouplevel diversification by taking into account the dependency structure between the risks of its subsidiaries and the risks of the parent company. In the following we use a group structure with a parent company at the top level (all the arguments are however equally true for holding company type groups).

"Down-streaming" of diversification: A parent company can down-stream grouplevel diversification via CRTIs (e.g. intra-group retrocession, guarantees, etc.) to its subsidiaries. A guarantee from the parent to a subsidiary allows a subsidiary to reduce the economic capital requirement but increases the capital requirement for the parent. If there is no formal instrument from the parent to the subsidiary, which ensures that 
the parent will support the subsidiary, then the subsidiary cannot benefit from being part of a group.

\section{What is an insurance group?}

For the purpose of this paper, an insurance group is defined as a collection of legal entities, which are all ultimately linked by ownership relations together with a web of CRTIs between the different legal entities.

The web of CRTIs is an essential part of a group. It defines how capital and risk flow between the different legal entities. Including CRTIs as a defining component of a group distinguishes the Swiss approach from a pure consolidated view, which sees capital and risk flowing freely within the group.

CRTIs determine how and in which circumstances a group supports or receives support from the legal entities. They are legally enforceable contractual agreements between the legal entities on how to share capital and risk.

CRTIs have to be legally enforceable contractual agreements between the legal entities that determine how and in which circumstances the legal entities share capital and risk.

\section{The case for group supervision}

The cornerstone of insurance regulation and supervision traditionally is the legal entity and the protection of policyholders', insureds' and beneficiaries' rights. Historically, insurance supervisors have mainly focused on the protection of policyholders in their own jurisdiction, which is the most easily accomplished by requiring that capital be physically present in the local jurisdiction. Considering insurance groups poses new challenges. How can one accomplish the natural goal of group supervision that all policyholders of an insurance group should be treated equally and fairly?

True risk-based solvency frameworks for insurance groups have been made possible only during the last years as the necessary computer power became available for the complex calculations to quantify the effects of guarantees and other CRTIs between legal entities in different jurisdictions.

In the past, supervisors were forced to take CRTIs into account by using rough approximations and often restricting their use in the calculation of the solvency requirements. With the increased capabilities and capacity of IT systems, it has become possible to take into account all material CRTIs even by small groups, and realistic economic modelling of a group's risk structure has become feasible.

An insurance regulator has to make a case for group supervision and explain its rationale. For the Swiss insurance regulator FOPI, the purpose of group supervision is not solely the setting of regulatory capital requirements on a group level. For FOPI, the risk of a group cannot be expressed by one number (the solvency ratio) only. It is necessary to know, besides the group's risk management processes, the risks and the solvency ratios of the different legal entities of the group. For this, at least the major legal entities need to be modelled on an economic framework. Therefore, for FOPI the analysis of a group's financial position requires that the solvency ratios of the major 
legal entities are quantified, taking into account the web of CRTIs between the group's legal entities.

\section{The consolidated approach}

While some groups' models use a consolidated approach, this implicitly implies that capital and risk flow freely between the legal entities of the group. While this might be a reasonable assumption when the financial situation of a group is good, the assumption will break down when the financial situation deteriorates. Then, not only will local supervisors prevent the transfer of assets, but the group is also likely to interpret its obligations in a more restrictive and legalistic manner. Capital will flow only when formal and legally binding agreements are in place. It is also difficult to render the consolidated approach consistent with an individual solvency test. The individual solvency test would also have to assume that capital flows freely from the group to the legal entity if the legal entity were to have financial problems, even if there were no legally binding CRTIs in place. It is difficult to imagine that a solo supervisor would accept such an assumption to reduce the Solvency Capital Requirement (SCR) of the legal entity, in particular if the group were situated in another jurisdiction. Inconsistent group level and individual solvency tests create paradoxical situations, for example a parent company would have two different capital requirements, one for the parent company as seen as a group and one seen as a solo entity.

\section{The CRTIs approach}

In a nutshell, the CRTIs approach that FOPI requires is based on the economic and realistic modelling of a group, seen as a collection of legal entities with its web of CRTIs. In contrast to the consolidated approach, restrictions on capital mobility have to be taken into account. Capital is assumed to flow between legal entities only according to legally enforceable and binding CRTIs. The CRTIs approach is explained in more detail below.

\section{Quantitative requirements}

The quantitative requirements on the CRTIs mean that they have to be taken into account appropriately in the solvency calculation of all involved legal entities. In case of a legal entity issuing a guarantee covering the potential shortfall of another legal entity, this would mean that the impact of the guarantee on the guarantor (leading to an increase in the SCR) and also on the legal entity receiving the guarantee has to be assessed (leading to a decrease in the SCR). This quantitative requirement implies that the risk situation of at least the major legal entities of the group have to be quantified.

\section{Qualitative requirements}

Qualitative requirements relate to risk management and corporate governance issues as well as to the appropriate contractual set-up and wording of CRTIs. A group needs 
to have sufficient resources, processes and know-how to handle the CRTIs. In particular for the legal entity reducing its SCR because of CRTIs (e.g. due to guarantees received), risk and capital management need to have realistic contingency plans for how to deal with such CRTIs, which would render the company undercapitalised if cancelled. Otherwise, the supervisor would have to declare such CRTIs as non-admissible. The wordings of the CRTIs need to be unambiguous and they have to be legally enforceable. In particular for legal entities situated in different jurisdiction, the group supervisor has to ensure that capital is actually fungible.

The quantitative requirements on CRTIs could in theory be supervised by the different local supervisors involved. However, the group supervisor has to have the overview over the different legal entities and can ensure that the legal entities' SCR is consistently determined. This is especially relevant if the legal entities are regulated in jurisdictions with methodologically inconsistent solvency frameworks.

To assess the qualitative requirements on CRTIs, supervision has to be done on a group level as local supervisors might not have access to the necessary information of the complete web of CRTIs.

\section{Supervisory powers}

For group supervision to be effective, it cannot simply be a coordinator between the different local supervisors. The group supervisor should also ensure that in case of financial distress, the interests of the policyholders of the group as a whole are served best. There is a natural tendency of local supervisors to restrict capital flows out of its jurisdiction exactly when capital mobility is most important. To counteract the predilection of local supervisors to focus mainly on policyholders in their own jurisdiction, the group supervisor ideally has the power to enforce capital mobility within the jurisdictions involved. For the group supervisor to be able to enforce capital flows to the different legal entities, the CRTIs need to be legally binding and satisfy the legal requirements of the different jurisdictions involved.

\section{Capital mobility}

Capital mobility is not an issue when the company is in a good financial state, but it becomes relevant mainly when the financial situation is deteriorating. This is however exactly the situation when capital mobility is likely to be restricted by local supervisors. Therefore the legal framework has to be strong enough that capital mobility is ensured when counteracting tendencies are at their strongest.

\section{Group capital requirements with an economic view}

The SST on a group level is based on an economic valuation of assets and liabilities of an insurance group. The SST is basically an instrument to analyse possible future economic states of the group. Conceptually, the group has to take into account its economic balance sheet given that adverse scenarios occur. Note that this is only a description of the methodology and does not mean that insurance groups have to use a scenario approach for quantifying the regulatory capital requirement. 


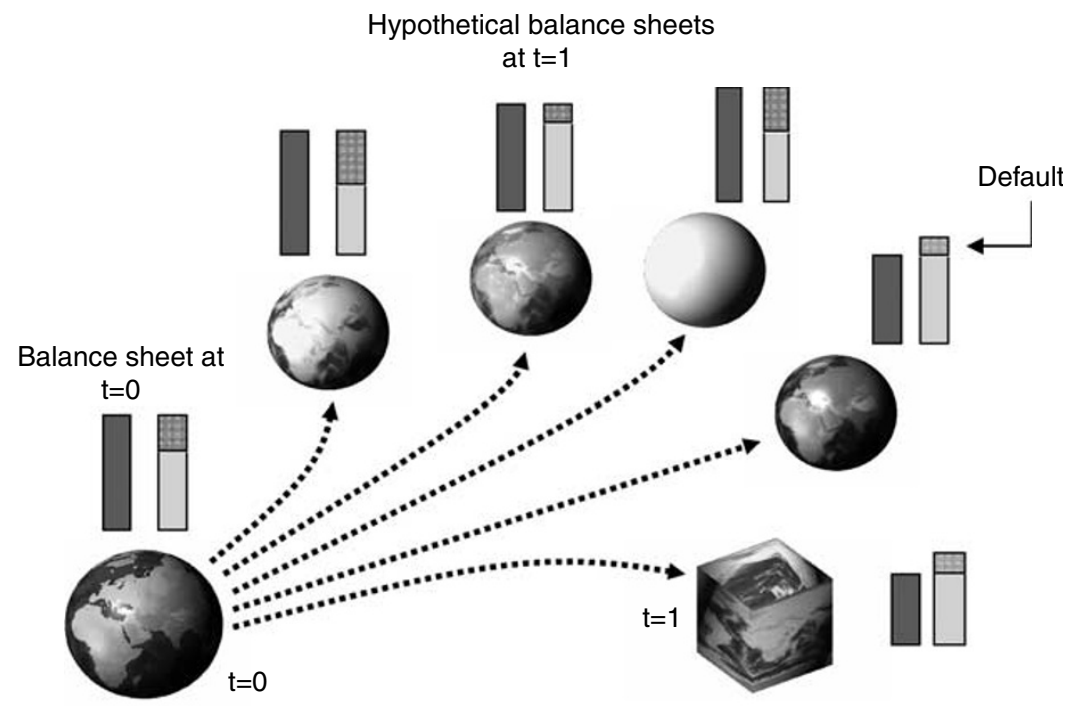

Figure 1. The SST on a group level.

The main idea is to consider the current economic balance sheet (at $t=0$ ) and the hypothetical future economic balance sheets at $t=1$ for the group.

The SCR is based on the risk of the change of available capital over a 1-year time horizon. The economic balance sheets determine the available capital under the different scenarios in 1 year's time. Hence they determine indirectly the SCR. (Figure 1)

Intuitively, the available capital of an insurer at time $t, A C(t)$, is defined as the economic value of its assets $V(A(t))$ less the economic value of its liabilities $V(L(t))$. Obviously, the value of both assets and liabilities depend on the state of the world, for example, the yield curves, the prices of stocks, the mortality experience of the company, etc. At a future time $t$, many different possible states of the world $\omega(t)$ are possible, whereas the current state at time $t=0, \omega(0)$ is known. We denote by $V(A(\omega)$ $(t)))$ and $V(L(\omega(t))$ the economic value of assets and liabilities, given a state of the world $\omega(t)$ at time $t$.

For the SST, risk is measured using the Tail Value at Risk over a 1-year time horizon on a confidence level of 1 per cent. The SCR is approximated by generating future states of the world $\omega_{1}(t), \ldots, \omega_{n}(t)$ and determining the change of available capital over a 1 -year time horizon. For each state of the world $\omega_{i}(t), i=1, \ldots, n$, the insurer has available capital $A C\left(\omega_{n}(t)\right)$. Without loss of generality, we assume that $A C\left(\omega_{1}(t)\right) \leqslant A C\left(\omega_{2}(t)\right) \leqslant \ldots \leqslant A C\left(\omega_{n}(t)\right)$. Then SCR is approximated by

$$
S C R \approx-\frac{1}{n \times 0.01} \sum_{i=1}^{n \times 0.01} A C\left(\omega_{i}(t)\right)-A C(w(0))
$$

The equation above says that SCR is defined as the average of the 1 per cent worst losses incurred over a 1-year time horizon. 
Available capital, and therefore the economic balance sheet given a future state of the world $\mathrm{SCR} \approx-\omega(t)$, depends on many factors. In particular for a legal entity of a group - a parent or a subsidiary - $A C(\omega(t))$ depends also on the CRTIs in place. In some states of the world, the legal entity might receive capital from other legal entities or it might have to transfer capital to other legal entities. If it owns subsidiaries, the value of these subsidiaries will depend on $\omega(t)$ as well.

An important corollary of the equation above is that SCR covers risk, while the economic balance sheet at $t=0$ gives a realistic, economic picture of the financial position of the company. Within the SST methodology, there is a clear distinction between the economic balance sheet and the SCR. The economic balance sheet gives the best possible description of the financial position of the company now. The SCR takes account of the risks that emanate during a 1-year time horizon. This is the reason why for the economic balance sheet there are no haircuts, assets that are not eligible, etc. If an asset were not eligible in certain future states of the world in 1 year's time for a legal entity (e.g. capital of a participation that might not be available anymore due to regulatory restrictions, goodwill, etc.), this would have to be and is taken into account in the calculation of the SCR.

If the financial position of a group, in particular of the parent company, is good, capital is likely to flow where it is needed and the group can be expected to support legal entities which might be in financial distress. Capital is easily transferable if the group as a whole is economically solvent. Therefore if the group is solvent, it can be considered as a consolidated entity where capital flows freely to where it is needed.

If the financial situation of the group deteriorates, the CRTIs approach assumes that the group's behavior switches from a consolidated to a legalistic one.

The SCR for the SST is defined as the TailVaR on the 1 per cent confidence level. That means - loosely speaking - that the SCR is driven by the 1 per cent worst economic outcomes. This is exactly the situation when the group cannot be considered as a consolidated entity anymore but as an entity that considers its obligations in a restrictive and legalistic way and will support its legal entities only if a formal agreement is in place.

If no CRTIs are in place between the legal entities of a group, available capital is not assumed to be transferable to a subsidiary in case of distress within the SST framework. However, the parent company always can obtain capital by selling its subsidiaries. The potential benefit of the subsidiaries of being members of a group depends purely on the willingness to pay of the parent company, which is not sufficient for FOPI.

The group-level model for the SST can be described succinctly as follows:

(1) Determine the economic balance sheets of each legal entity of the group at time $t=0$.

(2) Simulate a number of potential states of the world in 1 year's time $\omega_{i}(1), i=1, \ldots, n$, obeying the probabilities of the model.

(3) For each scenario $\omega_{I}(1)$, determine the economic balance sheets of the different legal entities. 
(a) If the financial position of the group under the scenario is bad, take into account the flow of capital and risk between the legal entities according to the CRTIs in place only. Possible restrictions in capital flow due to legal, regulatory or other reasons also have to be taken into account.

(b) If the financial position of the group under the scenario is good, it would be consistent to take into account that the group might transfer capital to legal entities even if no CRTIs are in place as long as it can be shown to FOPI that management would actually act in such a way.

(4) From (1) and (3) available and required capital for each legal entity can be determined.

To give up the distinction of the group's behavior with respect to the financial position (3(a) and 3(b)) and always assuming that the group behaves legalistically does in general not change the SCR materially, since SCR is driven mainly by the 1 per cent worst outcomes which have to be modelled according to 3(a).

Of course, FOPI does not demand that the actual model use the above methodology. A model can use different approaches and simplifications, as long as it can show to FOPI that it is faithful to the SST methodology and principles.

The economic balance sheet of a parent company in the group contains the market value of the legal entity it owns as an asset. There is no reason to deduct a possible regulatory requirement imposed on the legal entity (e.g. a local SCR) since the parent can sell the legal entity if necessary for its economic value. However, possible restrictions on capital flows from the legal entity to the parent have to be taken into account in the evaluation of the scenarios (under 3(a)).

It can be argued that assuming that a parent can always sell a legal entity it owns to unlock capital when needed might not be warranted if the financial situation of the group is deteriorating. The question is mainly one of liquidity. If the group needs the capital quickly to pay off a large claim, this is a valid argument. If claims have to be paid off over a longer time horizon, then it is not necessary to make a fire sale. If capital needs to be made available quickly, a sell-off might not be possible without incurring a large haircut on the economic value of the subsidiary. This has then to be taken into account in the model.

If a parent puts no guarantee to the legal entity it owns in place, it can take the limited liability put option into account. In that case, the value of the legal entity it owns cannot fall below zero.

\section{Group-level diversification}

The parent company benefits from group-level diversification since the random changes of the market value of its assets (which include participations, i.e., the values of subsidiaries) and liabilities are not fully correlated. Group-level diversification is effected via the ownership relation between the parent and its subsidiaries.

Figure 2 shows graphically how group-level diversification occurs. The capital necessary for the parent company to take on the risk during the following year is determined by the (stochastic) change of the economic balance sheet over 1 year. The economic capital of the parent is affected not only by its own liabilities but also by the economic value of the subsidiaries it owns. 

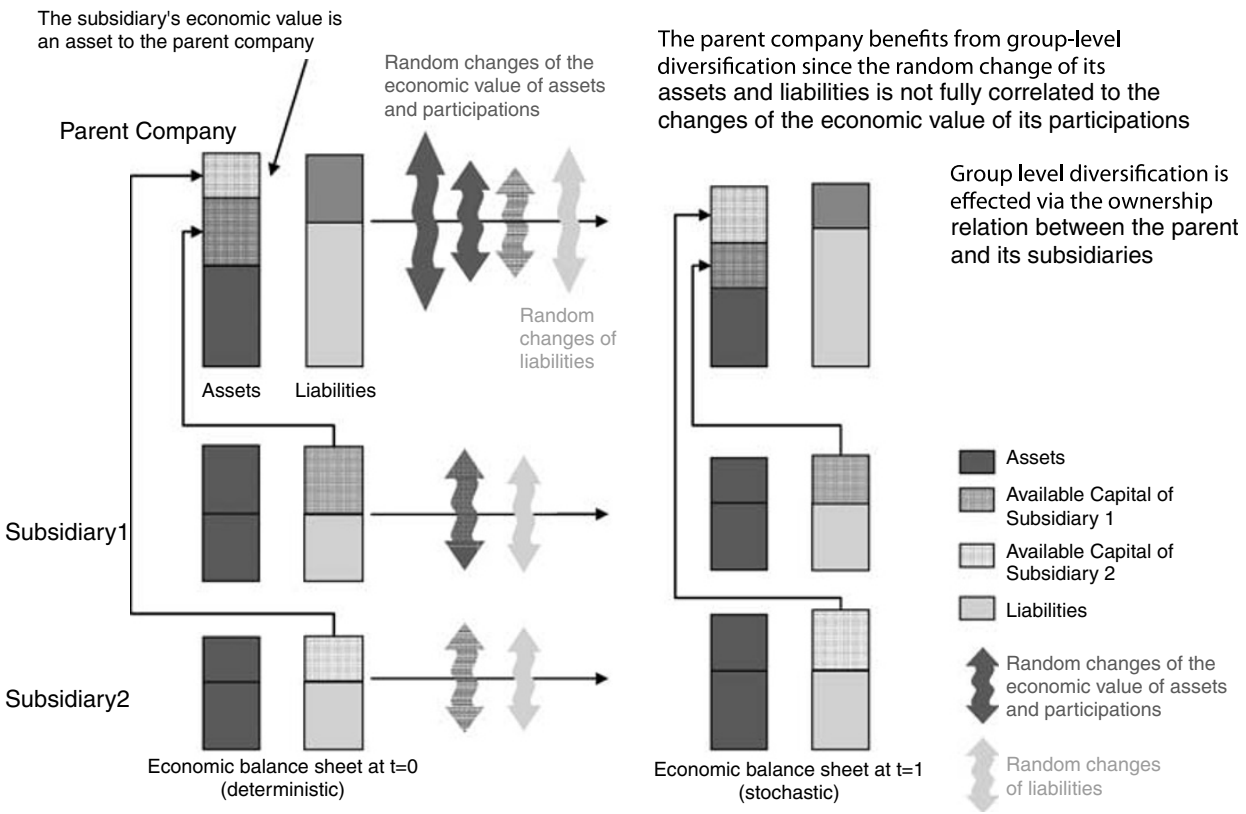

Figure 2. Group-level diversification.

\section{Down-streaming of diversification}

A subsidiary can benefit from being part of the group if the parent company puts corresponding CRTIs in place. For instance, if the parent company gives the subsidiary a guarantee to support it in case of financial problems, this allows the subsidiary to reduce its SCR since the hypothetical economic balance sheets in 1 year's time have to take into account the fact that the parent will support the subsidiary if the guarantee is triggered. This results in an increase of available capital under all states of the world where the guarantee will be triggered, and therefore reduces the SCR of the subsidiary.

The reduction of the risk-based capital requirement of the subsidiary is bought with an increase in the capital requirement of the parent company since the parent's SCR has the additional risk that the guarantee will be invoked by the subsidiary.

The ability of the parent company to issue guarantees to its subsidiaries is constrained by its capital situation since each guarantee (or more generally, the CRTIs that transfer risk from subsidiaries to the parent) increases the capital requirement of the parent.

\section{Treatment of CRTIs}

CRTIs allow for the efficient risk and capital management of a group. For example, a guarantee can transfer the risk of a subsidiary to the parent company and reduce the risk - and therefore the SCR - of the subsidiary. However, for the SCR of a subsidiary 
to be reduced, the guarantee has to be legally binding and enforceable. That means in particular that the wording of the CRTIs has to be unambiguous and have a clearly defined trigger. The guarantor needs to be able to assess the impact of the guarantee on its SCR. While in the past some groups have issued guarantees with a certain degree of insouciance, the fact that within the SST the guarantor incurs a cost (in many cases mainly an increase in SCR) will limit the amount of guarantees issued.

\section{Example}

We consider a simple group consisting of one parent and one subsidiary. The parent issues a guarantee to the subsidiary. We assume that the subsidiary is capitalised up to a fraction of the SCR while the remainder $((1-a) * \mathrm{SCR})$ is covered by the guarantee. The SCR is understood to be calculated on a stand-alone basis, that is, not taking the guarantee into account. If the subsidiary's capital falls below zero, the parent comes up for the shortfall up to the guarantee's capacity. The parent will only pay up to such an amount that its own capital stays positive. In the Figure 3 the capacity of the guarantee ranges from 0 per cent of the subsidiary's SCR up to 100 per cent of SCR. SCR is defined as TailVaR with a 1 per cent confidence level. The claims of both parent and subsidiary are assumed to be independent and normally distributed with mean 0 and variance 1 . The value of the guarantee also depends strongly on the parent's solvency ratio, which determines its ability to pay.

\section{Requirements on CRTIs}

For cases where a substantial part of a legal entity's SCR is reduced via a parental guarantee (or a similar CRTIs), the requirements on the legal enforceability, the

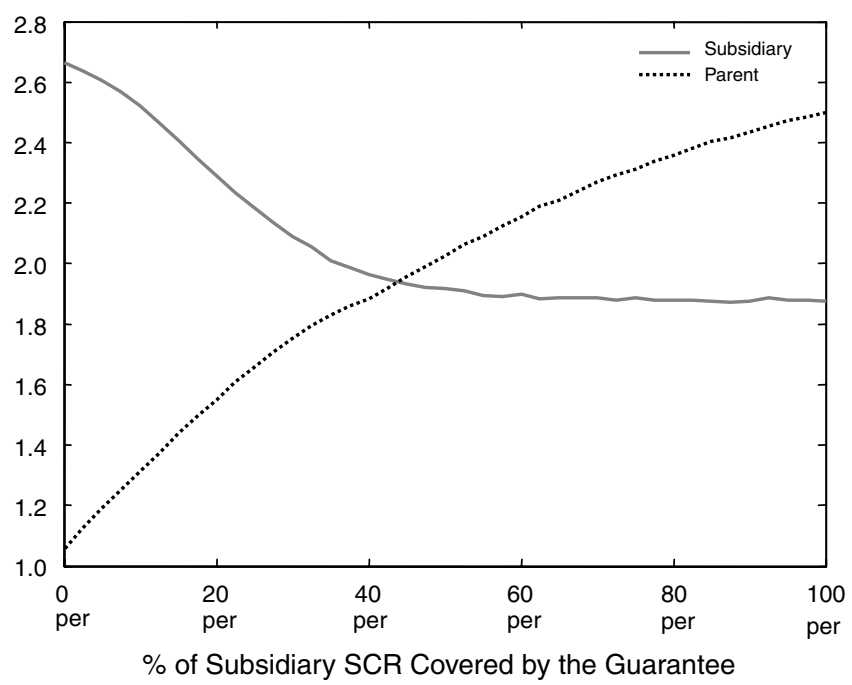

Figure 3. SCR of parent and subsidiary. 
wording and quantification are commensurate. For the regulatory acceptability of such a CRTIs, the necessary prerequisites have to be satisfied first. It has to be clear that parent has sufficient capital to be able to serve the guarantee with sufficient likelihood. It has to be shown that there are no legal impediments for the transfer of capital, for example restrictions due to shareholder rights, due to the supervisor of the parent company, etc.

Both the parent and the subsidiary need to be able to quantify the effect of the guarantee on their SCR in a consistent way and their risk and capital management must be able to handle the CRTIs employed.

The subsidiary needs to have a formal strategy in place on how to cope with the situation that the parent might cancel the guarantee. Normally guarantees are not permanent and can be cancelled by the guarantor. After the notification period, the subsidiary's risk and capital management is responsible for achieving a solvent state after such a cancellation. In particular for intra-group guarantees, it is important that senior management and the board of a legal entity that reduces its SCR due to the CRTIs be aware of its responsibility to be economically solvent.

\section{References}

Bundesamt für Privatversicherungen (BPV) (2006) Draft Modelling of Groups and Group Effects, Bern: Bundesamt für Privatversicherungen (BPV).

The Chief Risk Officer Forum (2005) A Framework for Incorporating Diversification in the Solvency Assessment of Insurers, 10 June.

HM Treasury \& FSA (2006) Supervising insurance groups under solvency II, A discussion paper (November). Luder, T. (2007) Modelling of Risks in Insurance Groups for the Swiss Solvency Test, Zurich: Swiss Actuarial Association.

\section{About the author}

Philipp Keller is the Head of Research and Development at the Federal Office of Private Insurance (FOPI) in Bern, Switzerland. 